\title{
Activation of the SIGRIS monitoring system for ground deformation mapping during the Emilia 2012 seismic sequence, using COSMO-SkyMed InSAR data
}

\author{
${ }^{1}$ Istituto Nazionale di Geofisica e Vulcanologia, Centro Nazionale Terremoti, Roma, Italy \\ ${ }^{2}$ Dipartimento della Protezione Civile, Ufficio Rischio Sismico, Roma, Italy \\ ${ }^{3}$ Agenzia Spaziale Italiana, Unità Osservazione della Terra, Roma, Italy
}

Stefano Salvi ${ }^{1}{ }^{\star}$, Cristiano Tolomei ${ }^{1}$, John Peter Merryman Boncori ${ }^{1}$, Giuseppe Pezzo ${ }^{1}$, Simone Atzori ${ }^{1}$, Andrea Antonioli ${ }^{1}$, Elisa Trasatti $^{1}$, Roberta Giuliani ${ }^{2}$, Simona Zoffoli ${ }^{3}$, Alessandro Coletta ${ }^{3}$

\section{Article history}

Received August 3, 2012; accepted August 22, 2012.

Subject classification:

SAR interferometry, Co-seismic displacement, Earthquakes, SIGRIS system, Italy.

\section{Introduction}

On May 20, 2012, at 02:03 UTC, a moderate earthquake of local magnitude, $\mathrm{M}_{\mathrm{L}} 5.9$ started a seismic sequence in the central Po Plain of northern Italy (Figure 1) [Scognamiglio et al. 2012, this volume]. The mainshock occurred in an area where seismicity of comparable magnitude has neither been recorded nor reported in the historical record over the last 1,000 years [Rovida et al. 2011].

The aftershock sequence evolved rapidly near the epicenter, with diminishing magnitudes until May 29, 2012, when at 07:00 UTC a large earthquake of $\mathrm{M}_{\mathrm{L}} 5.8$ occurred $12 \mathrm{~km}$ WSW of the mainshock, starting a new seismic sequence in the western area (Figure 1); a total of seven earthquakes with $M_{L}>5$ occurred in the area between May 20 and June 3, 2012 (Figure 1). The details of the seismic sequence can be found in the report by Scognamiglio et al. [2012].

Immediately after the mainshock, the Italian Department of Civil Protection (Dipartimento di Protezione Civile; DPC) requested the Italian Space Agency (Agenzia Spaziale Italiana; ASI) to activate the Constellation of Small Satellites for Mediterranean Basin Observation (COSMOSkyMed) to provide Interferometric Synthetic Aperture Radar (InSAR) coverage of the area. COSMO-SkyMed consists of four satellites in a 16-day repeat-pass cycle, with each carrying the same SAR payload [Italian Space Agency 2007]. In the current orbital configuration, within each 16day cycle, image pairs with temporal baselines of 1, 3, 4 and 8 days can be formed from the images acquired by the four different sensors. Combined with the availability of a wide range of electronically steered antenna beams with incidence angles ranging from about $16^{\circ}$ to $50^{\circ}$ at near-range [E-geos 2012], this capability allows trade-offs between tem- poral and spatial coverage to be exploited during acquisition planning.

A joint team involving the Istituto Nazionale di Geofisica e Vulcanologia (INGV; National Institute of Geophysics and Volcanology) and the Istituto per il Rilevamento Elettromagnetico dell'Ambiente (IREA-CNR; Institute for the Electromagnetic Sensing of the Environment) was activated to generate InSAR-based scientific products to support the emergency management. In this framework, the ASI and DPC requested that INGV activated the Spacebased Monitoring System for Seismic Risk Management (SIGRIS) [Salvi et al. 2010]. SIGRIS consists of a hardware/software infrastructure that is designed to provide the DPC with value-added information products in the different phases of the seismic cycle. During earthquake emergencies, its goal is to rapidly provide decision-support products, such as validated ground-displacement maps and seismic source models.

This study reports the details of the activation of the SIGRIS system in the case of the Emilia sequence. It provides a description of the COSMO-SkyMed datasets and processing procedures, as well as selected interferometric results for the coseismic and post-seismic ground deformation. Fault modeling results for the seismic sources of the largest earthquakes, and a more detailed discussion of the observed ground deformations are reported in Pezzo et al. [2012].

\section{The SIGRIS monitoring system}

The SIGRIS system was developed within a pilot project of the ASI that was aimed at demonstrating the operational use of Earth observation satellite data in the seismic risk management decision chain [Salvi et al. 2010]. SIGRIS con- 


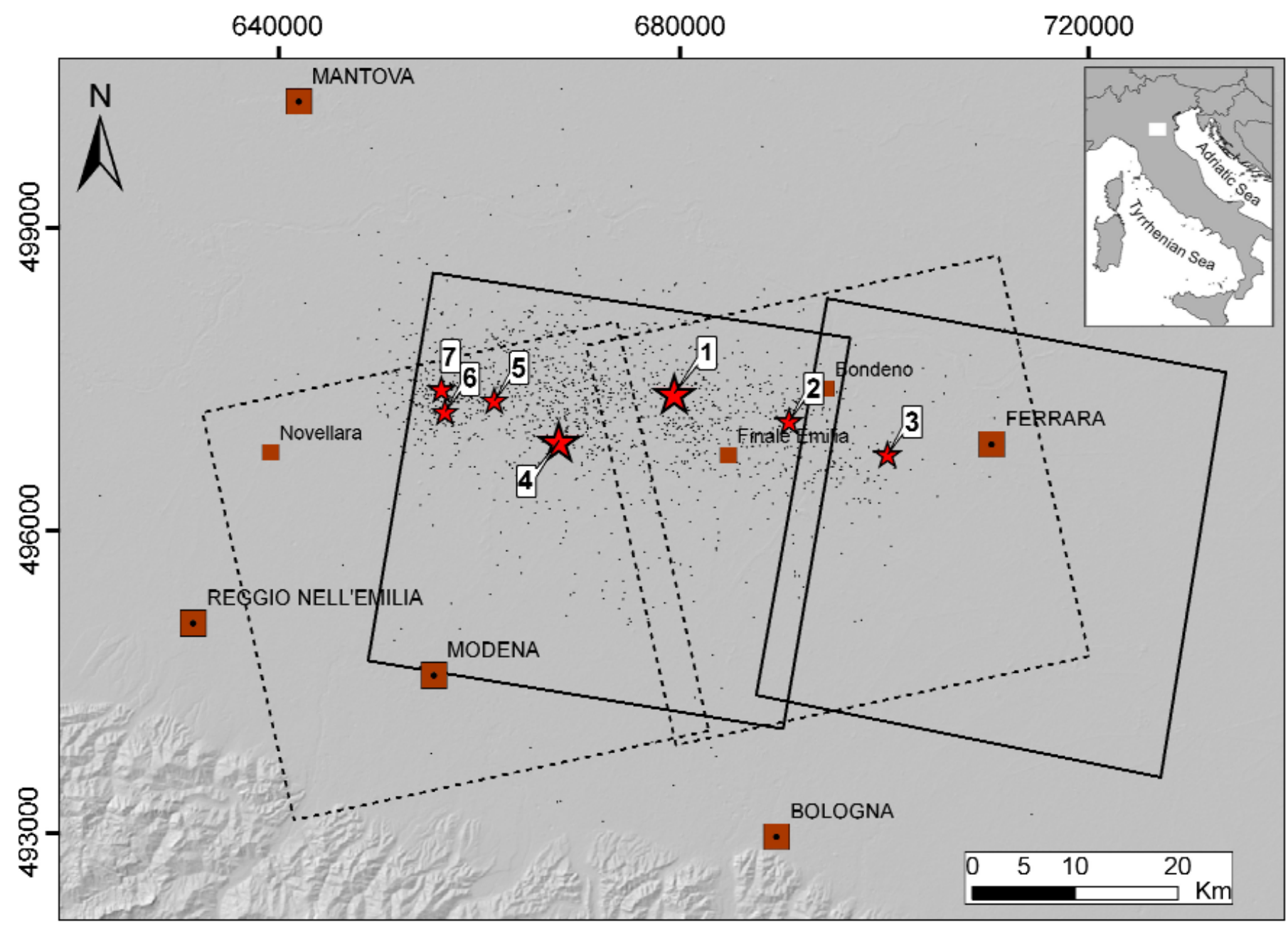

Figure 1. The area of the 2012 seismic sequence. Stars, largest events of the sequence, numbered in order of occurrence; 1, May 20, 2012, $\mathrm{M}_{\mathrm{L}} 5.9$ event; 4, May 29, 2012, $M_{L} 5.8$ event; small dots, selection of smaller aftershocks. The outline boxes (dotted for the ascending orbit, continuous for the descending orbit) show the strip-map COSMO-SkyMed scenes used to cover the epicentral area.

tains a comprehensive and integrated set of software tools (either commercial or developed ad hoc within the project framework) and standardized procedures, dedicated to the following:

- Efficient archiving and management of large amounts of satellite images;

- Processing of optical and SAR imagery using a wide selection of state-of-the-art algorithms;

- Generation of standardized and validated geophysical products (e.g., ground-displacement maps);

- Generation of models of the monitored geophysical phenomena (e.g., earthquake source models).

The SIGRIS system was first operationally tested by the DPC during a demonstration phase that involved the generation of products for the L'Aquila seismic sequence [Atzori et al. 2009], and after that, it was applied to several seismic events worldwide (www.sigris.it). The SIGRIS system is operated by INGV researchers and is activated by the DPC for seismic emergencies in Italy, and by the INGV, in agreement with the ASI, for emergencies outside the Italian territory. The activation request is usually sent by email (all actions need to be logged for future reference), and this triggers a rapid chain of events that is summarized below with reference to Italian crises and the COSMO-SkyMed imagery (at present the preferred sensor for the system):

- The SAR image archive is analyzed and a listing of preevent images is generated. For sensors with several acquisition modes, like COSMO-SkyMed, this step is needed to program post-seismic acquisitions that match the geometry of the pre-seismic acquisitions, to allow subsequent InSAR processing.

- Based on the archive analysis and the characteristics of the seismic sequence, an initial acquisition request is then submitted to the ASI. The request is jointly prepared by the research centers supporting the DPC during the emergency (the so-called 'DPC-competence centers'), namely the INGV and the IREA-CNR in the case of the Emilia sequence.

- Following the preparation of an acquisition feasibility study by the ASI, the final acquisition plan is defined for the first few months. At some time during the crisis, the DPC will fix the actual COSMO-SkyMed monitoring time-frame in agreement with the duration of the seismic emergency, as declared by the Italian government. Note that the first acquisition planning is usually updated, and sometimes largely 
modified, during the progress of the seismic sequence, following the spatial evolution of the seismicity (e.g., if a large aftershock occurs in other areas), and possible alerts for nearby fault activation.

- Following the image acquisition, the ASI delivers the imagery to the competence centers for data processing. Typically focused image frames are provided (Single-look Complex Slant [SCS] product), although unfocused data strips (RAW product) can be requested for specific purposes. The time delay between image acquisition and delivery is usually a few hours. StripMap HIMAGE is the preferred acquisition mode. A standard image frame has a size of $40 \mathrm{~km} \times$ $40 \mathrm{~km}$ and a $3 \mathrm{~m} \times 3 \mathrm{~m}$ resolution on the ground, for a $40^{\circ}$ incidence angle.

- After image delivery, the competence centers process the data, validate the results, and deliver them to the DPC. Product validation is carried out using the available ancillary information and data, and the seismological and geological knowledge of the operator. Using the SIGRIS system, the INGV can generate and deliver products in a very short time; the first ground displacement maps can be delivered to the DPC within $1.5 \mathrm{~h}$ after the image download from the ASI ftp site. Further products based on the same InSAR datasets are then delivered in successive versions with incremental validation levels, following the flow of the ancillary information used for product validation (e.g., global positioning system [GPS], seismicity, focal mechanism parameters, subsurface geophysics, geology, field survey). These successive product versions are generated in a time frame ranging from $1 \mathrm{~h}$ to a few days.

While for the COSMO-SkyMed data the DPC issues high priority image requests directly to the ASI, for the Emilia emergency it also activated the European Global Monitoring for Environment and Security (GMES) Emergency Management Service [see http://portal.emsgmes.eu], which can provide reference maps and damage maps using archive and post-event Earth observation data from other sensors. In this case the EMS provided damage maps based on pre-event and post-event high-resolution optical sensors; no archive TerraSAR-X data were available for change detection analysis.

\section{InSAR data processing and first results}

The area struck by the earthquakes is a flat alluvial plain that is intensely cultivated for most of the year. This causes a relatively rapid variation of the surface scattering properties, to which the X-band COSMO-SkyMed wavelength (about $3 \mathrm{~cm}$ ) is particularly sensitive [Franceschetti and Lanari 1999]. For this reason, most SAR interferograms with temporal baseline longer then ca. 16 days are affected by considerable loss of coherence, and cannot be used to extract quantitative ground displacement information with InSAR techniques.

Since the end of 2010, a nationwide monitoring plan named Map Italy has been developed by the ASI, in cooperation with the competence centers (INGV, International Centre on Environmental Monitoring [CIMA] Foundation, Politecnico di Milano [Polimi], and IREA-CNR), following a request from the DPC. The goal of the plan was to cover all land areas of Italy with COSMO-SkyMed strip-map imagery, to provide a best effort revisit time of 16 days for the creation of an archive for the management of hydrological, volcanic and seismic emergencies. The continuity of the Map Italy archive is extremely important for InSAR applications, including both standard two-pass and multitemporal (time-series) applications.

After May 20, 2012, an emergency acquisition plan was designed to provide ascending and descending acquisitions over the epicentral area. After an in-depth analysis, it was decided to continue with the Map Italy acquisition scheme, the only difference being the top acquisition priority, which allowed any possible acquisition conflict to be overcome. Any modification to the Map Italy plan, such as a change of beam, would disrupt the continuity of the image archive for the entire several-hundred-kilometer-long ground track for a period of a few to several months, and it could jeopardize future InSAR applications over a large area.

The plan scheduled rigorous 16-day acquisitions from adjacent ground tracks using three ascending (H4-03, H4-04, H4-05) and two descending beams (H4-03, H4-04). This plan was modified at the end of June, to enlarge the monitored area to the west and east of the epicentral area, using 8-day acquisitions from two ascending and two descending beams

\begin{tabular}{|c|c|c|c|c|c|c|}
\hline $\begin{array}{c}\text { Interf } \\
\text { no. }\end{array}$ & Orbit & $\begin{array}{c}\text { Incidence } \\
\text { angle }\end{array}$ & $\begin{array}{l}\text { Temporal } \\
\text { baseline }\end{array}$ & $\begin{array}{l}\text { Perpendicular } \\
\text { baseline }\end{array}$ & $\begin{array}{c}\text { Earthquakes } \\
\text { included }\end{array}$ & $\begin{array}{l}\text { Delivery date } \\
\text { (to the DPC) }\end{array}$ \\
\hline 1 & $\mathrm{D}$ & $29^{\circ}$ & May 19 - May 23 & $365 \mathrm{~m}$ & $1,2,3$ & May 24th \\
\hline 2 & $\mathrm{D}$ & $32^{\circ}$ & May 27 - June 4 & $425 \mathrm{~m}$ & $4,5,6,7$ & June 6th \\
\hline 3 & A & $29^{\circ}$ & May 30 - June 7 & $134 \mathrm{~m}$ & 7 & - \\
\hline 4 & A & $40^{\circ}$ & May 22 - May 26 & $473 \mathrm{~m}$ & - & - \\
\hline
\end{tabular}

Table 1. COSMO-Skymed interferograms, as detailed in the text. ${ }^{\star}$ Earthquakes included in each time period are referred to in Figure 1. 

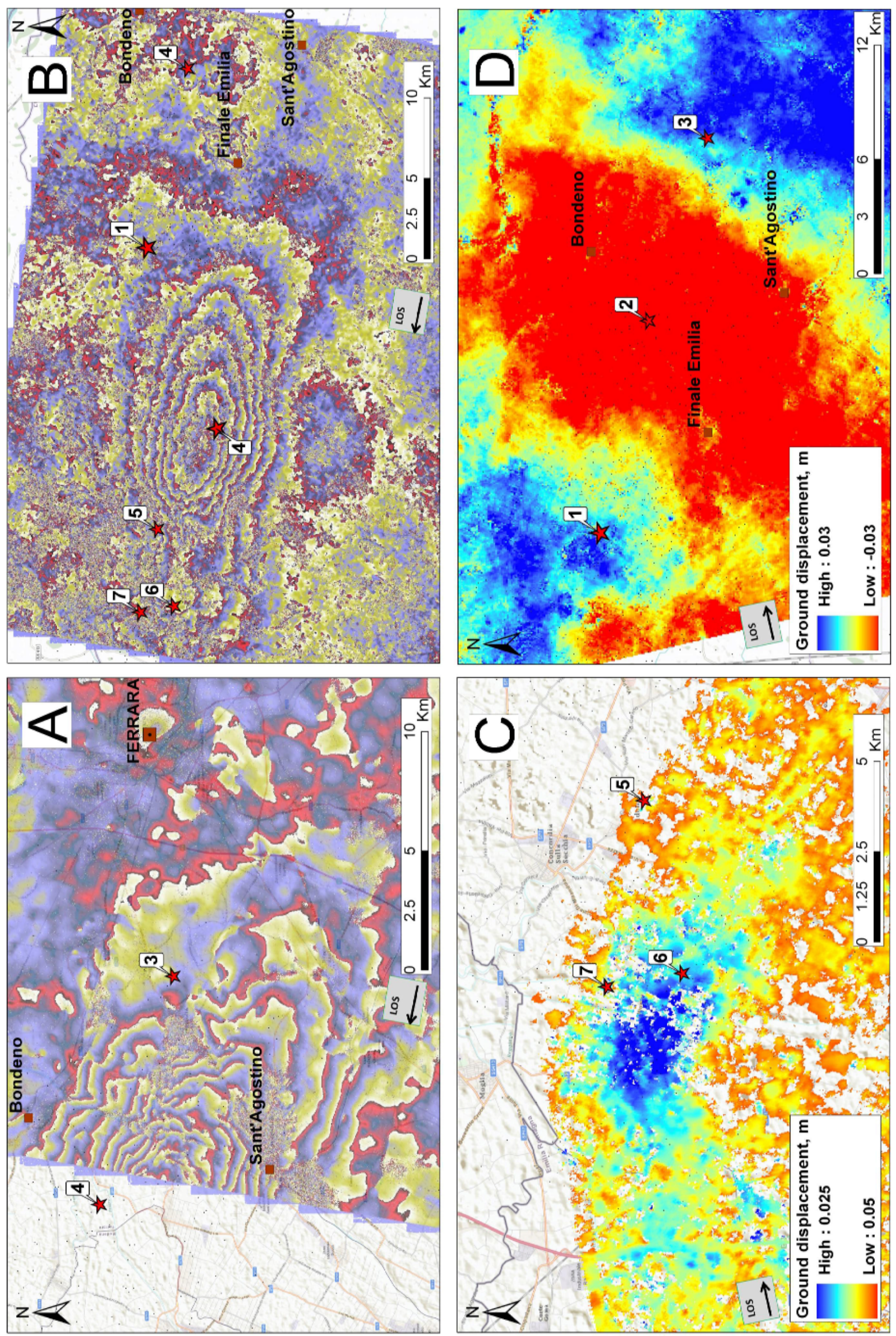

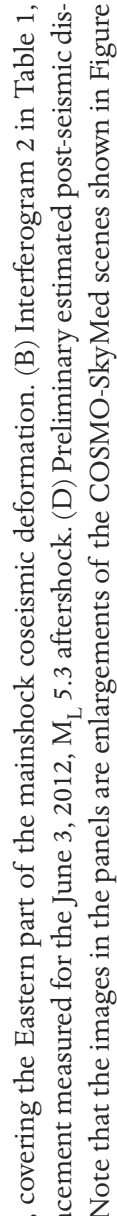

$\rightarrow \pi$

들

च :

क्ष प्र

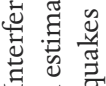

ङ

ษิ)

항

.

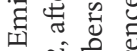

छี

के จे

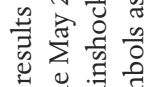

플 त्ञ

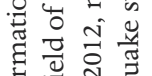

苋苞完

च हु

ठ․

bo 0

过 司 颔

i 00 逮

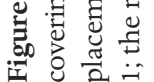


not included in Map Italy. Over 50 strip-map images were acquired up to the end of July. An updated overview (in ESRI Shapefiles or KML format) of all of the COSMO-SkyMed images acquired in the area can be obtained by querying the $\mathrm{E}$ GEOS catalog at the following web address: http://87.241. 31.78/index.php.

In Table 1, we have listed the most significant coseismic and post-seismic interferograms that were processed during the first 15 days of the emergency. For the interferograms and displacement maps delivered as validated SIGRIS products, we also provide the dates of delivery to the DPC. We processed all of the datasets at $25 \mathrm{~m}$ resolution, and used the 3 arc second Shuttle Radar Topography Mission digital elevation model for topography subtraction. Orbital ramps were removed in most of the interferograms, and were estimated from areas not affected by evident deformation.

Figure 2A shows the first coherent coseismic interferogram that spanned the May 20, 2012, event, which was generated on May 24, 2012, from the first image pair listed in Table 1 . The concentric fringe pattern at the western border of the scene represents a portion of the displacement field of the May 20, 2012, mainshock (note that this pair also spans two $M_{L} 5.1$ aftershocks; Figure 1, events 2, 3). The maximum surface deformation was ca. $15 \mathrm{~cm}$ towards the satellite. The line-of-sight (LOS) from the satellite to the ground was inclined $29^{\circ}$ from the vertical, and was oriented as indicated by the black arrow in Figure 2A.

Deviations from the concentric fringe pattern are due to local ground-deformation effects and to decorrelation (e.g., from Sant'Agostino to the northeast). Most of these features are spatially associated to localized ground displacement of superficial origin observed in the field, such as widespread soil liquefaction phenomena and water-table variations [Emergeo Working Group 2012].

Figure $2 \mathrm{~B}$ shows interferogram no. 2 of Table 1, which encompasses the $M_{L} 5.8$ aftershock of May 29, 2012. In this case, the entire displacement field is visible. A clear bull's-eye pattern is centered on the epicenter of the May 29, 2012, aftershock, although there is a smaller, secondary maximum to the west, where three more aftershocks of $\mathrm{M}_{\mathrm{L}} 5.1$ to 5.3 occurred (Figure 1, events 5, 6, 7). The displacement map (not shown) [see Pezzo et al. 2012] shows a maximum LOS uplift of $10 \mathrm{~cm}$, and negative ground movement of up to $-4 \mathrm{~cm}$ to the south. Fewer local fringe distortions can be seen in this interferogram, in agreement with the limited number of surface geological effects observed in the field after this earthquake [Emergeo Working Group 2012].

The pattern of coseismic ground deformation observed in the COSMO-SkyMed interferograms is in good agreement with the seismological results, which indicates activation of $\mathrm{E}-\mathrm{W}$ thrust faults at intermediate depths [Malagnini et al. 2012]. The relative displacement data are expected to have an error standard deviation of better than $1 \mathrm{~cm}$, based on measured displacements away from the main deformation areas, and they have been used for seismic-source modeling [Pezzo et al. 2012], as well as for the interpretation of surface geological effects [Emergeo Working Group 2012].

A further, wider coverage of the ground displacement fields of all of the main events of the sequence was provided by a Radarsat- 1 interferogram, which was made available to the National Civil Protection Service by the Tele-Rilevamento Europa company [http:/ /www.treuropa.com/Home/ NewsedEventi/News/tabid/59/newsid988/258/Default. aspx].When combined with the COSMO-SkyMed results, the Radarsat data allowed the details of coseismic and aseismic deformation that occurred during the sequence to be investigated [Pezzo et al. 2012].

Figure $2 \mathrm{C}$ shows the ground displacement that occurred between May 30 and June 7, 2012 (see Table 1). This map contains the coseismic deformation related to the $M_{L} 5.1$ aftershock that occurred on June 3, 2012, at the western limit of the epicentral area (Figure 1, event 7) [INGV 2012]. A clear small uplift pattern is visible, with maximum LOS displacement of ca. $1.5 \mathrm{~cm}$.

Figure 2D shows the ground displacement unwrapped from interferogram 4 in Table 1 . It covers a 5 -day post-seismic period following the May 20, 2012, mainshock. The ca. $10-\mathrm{km}$-wide NE-trending belt visible in the center of the image indicates ground lowering (in the LOS) by up to ca. $2 \mathrm{~cm}$, while the areas NW and SW of the image are uplifting. This signal shows a peculiar pattern (i.e., it does not follow the E-W trend of the co-seismic displacement field), and it needs to be confirmed by cross-validation with GPS data [Serpelloni et al. 2012, this volume], although it appears improbable that it might be generated by tropospheric effects. This is shown here as a preliminary result, noting that the post-seismic displacement trend follows the location of some important paleo-riverbeds along which important and diffuse ground effects were observed (soil liquefaction and fracturing), due to shallow water table excitation [Emergeo Working Group 2012].

\section{Conclusions}

The ground displacement related to the main events of the Emilia seismic sequence was accurately measured by COSMO-SkyMed imagery, although the spatial and temporal coverage of the displacement field of the largest events was reduced by the changeable surface scattering properties, These can limit the interferometric coherence for image pairs with temporal baselines longer than 16 days. This outlines the importance of maintaining temporally dense image archives with constant revisit times (optimally less than 16 days) over tectonically active areas.

The mapped coseismic ground displacements confirm the activation of shallow thrust faults of the Mirandola and Ferrarese fold belts [Pezzo et al. 2012], and preliminary data 
of post-seismic deformation show the presence of detectable signals. A joint analysis of InSAR and GPS post-seismic time series will be carried out when a sufficient number of images has been acquired (at least 15).

The good monitoring capacities of the COSMOSkyMed constellation were again confirmed: the first interferogram, although noisy, was released only 2 days after the mainshock. The first significant displacement data were released 4 days after the event, and the preliminary source models shortly afterwards. Although the near-real-time monitoring capacity can be further improved, by reducing the time to physical delivery of the image files after acquisition, this timing is an order of magnitude better than has been possible so far using other SAR satellites (ERS / ENVISAT, ALOS, Radarsat).

InSAR operational monitoring of the earthquake ground deformation during the coseismic and post-seismic periods is today feasible using SAR satellite constellations as COSMOSkyMed, provided that suitable image archives are maintained. In the case of sub-optimal image availability, the best results to support emergency management can be obtained by exploiting the synergetic use of multiple satellite sensors in different bands and geometries [Pezzo et al. 2012].

Acknowledgements. COSMO-SkyMed images are the copyright of ASI. G.P. and J.P.M.B. were supported by the SIGRIS contract. We thank E. Sansosti and his team at IREA-CNR for sharing their InSAR results during the emergency activity. We thank two anonymous referees for their insightful and constructive comments.

\section{References}

Atzori, S., I. Hunstad, M. Chini, S. Salvi, C. Tolomei, C. Bignami, S. Stramondo, E. Trasatti, A. Antonioli and E. Boschi (2009). Finite fault inversion of DInSAR coseismic displacement of the 2009 L'Aquila earthquake (Central Italy), Geophys. Res. Lett., 36, L15305; doi:10.1029/2009 GL039293.

E-geos (2012). COSMO-SkyMed FAQ; available online at http:/ / www.eurimage.com/products/ cosmo.html

Emergeo Working Group (2012). Coseismic geological effects associated with the Emilia earthquake sequence of May-June 2012 (northern Italy), Nat. Haz. Earth Syst. Sci., under review.

Franceschetti, G., and R. Lanari (1999). Synthetic aperture RADAR processing, CRC Press, Boca Raton, Fla. ISBN 08493-7899-0.

INGV (2012). Italian seismological instrumental and parametric database, ISIDE; http: / / iside.rm.ingv.it

Italian Space Agency (2007). COSMO-SkyMed System Description and User Guide; available online at: http: / www. asi.it/files / CSK $\% 20$ SYSTEM $\% 20$ DESCRIPTION\%20\% 20USERS\%20GUIDE.pdf

Malagnini, L., R.B. Herrmann, I. Munafò, M. Anselmi, M. Buttinelli, A. Akinci and E. Boschi (2012). The 2012 Fer- rara Seismic Sequence: Regional Crustal Structure, Earthquake Sources, and Seismic Hazard, in press on Geophys. Res. Lett.; doi:10.1029/2012GL053214.

Pezzo, G., C. Tolomei, J.P. Merryman Boncori, S. Salvi, S. Atzori, A. Antonioli, E. Trasatti, F. Novali, E. Serpelloni, L. Candela and R. Giuliani (2012). Coseismic deformation and source modelling of the May 2012 Emilia (Northern Italy) earthquakes, Geophys. J. Int., under review.

Rovida, R., P. Camassi, P. Gasperini and M. Stucchi, eds. (2011). CPTI11, the 2011 version of the Parametric Catalogue of Italian Earthquakes, Milano/Bologna; http:/ / emidius.mi.ingvit/CPTI

Salvi, S., S. Vignoli, M. Serra and S. Zoffoli (2010). Use of satellite SAR data for seismic risk management: results from the pre-operational ASI-SIGRIS Project, Proc. ESA Living Planet Symposium, Bergen, NO, ESA SP-686.

Scognamiglio, L., L. Margheriti, F.M. Mele, E. Tinti, A. Bono, P. De Gori, V. Lauciani, F.P. Lucente, A.G. Mandiello, C. Marcocci, S. Mazza, S. Pintore and M. Quintiliani (2012). The 2012 Pianura Padana Emiliana seimic sequence: 1ocations, moment tensors and magnitudes, Annals of Geophysics, 55 (4); doi:10.4401/ag-6159.

Serpelloni, E., L. Anderlini, A. Avallone, V. Cannelli, A. Cavaliere, D. Cheloni, C. D'Ambrosio, E. D'Anastasio, A. Esposito, G. Pietrantonio, A.R. Pisani, M. Anzidei, G. Cecere, N. D'Agostino, S. Del Mese, R. Devoti, A. Galvani, A. Massucci, D. Melini, F. Riguzzi, G. Selvaggi and V. Sepe (2012). GPS observations of coseismic deformation following the 2012, May 20 and 29 Emilia seismic events (northern Italy): data, analysis and preliminary models, Annals of Geophysics, 55 (4); doi:10.4401/ag-6168.

\footnotetext{
${ }^{\star}$ Corresponding author: Stefano Salvi, Istituto Nazionale di Geofisica e Vulcanologia, Centro Nazionale Terremoti, Roma, Italy; email: stefano.salvi@ingv.it.

(C) 2012 by the Istituto Nazionale di Geofisica e Vulcanologia. All rights reserved.
} 